\title{
Iron bioavailability to phytoplankton: an empirical approach
}

\author{
Hagar Lis ${ }^{1,2}$, Yeala Shaked ${ }^{1,2}$, Chana Kranzler ${ }^{1,3}$, Nir Keren ${ }^{3}$ and François MM Morel ${ }^{4}$ \\ ${ }^{1}$ Interuniversity Institute for Marine Sciences, Eilat, Israel; ${ }^{2}$ The Freddy and Nadine Herrmann Institute of \\ Earth Sciences, Edmond J. Safra Campus, Givat Ram, Hebrew University, Jerusalem, Israel; ${ }^{3}$ Department of \\ Plant and Environmental Sciences, The Alexander Silberman Institute of Life Sciences, Edmond J. Safra \\ Campus, Givat Ram, Hebrew University, Jerusalem, Israel and ${ }^{4}$ Department of Geosciences, Guyot Hall, \\ Princeton University, Princeton, NJ, USA
}

\begin{abstract}
Phytoplankton are often limited by iron in aquatic environments. Here we examine Fe bioavailability to phytoplankton by analyzing iron uptake from various Fe substrates by several species of phytoplankton grown under conditions of Fe limitation and comparing the measured uptake rate constants (Fe uptake rate/ substrate concentration). When unchelated iron, Fe', buffered by an excess of the chelating agent EDTA is used as the Fe substrate, the uptake rate constants of all the eukaryotic phytoplankton species are tightly correlated and proportional to their respective surface areas (S.A.). The same is true when FeDFB is the substrate, but the corresponding uptake constants are one thousand times smaller than for $\mathrm{Fe}^{\prime}$. The uptake rate constants for the other substrates we examined fall mostly between the values for $\mathrm{Fe}^{\prime}$ and FeDFB for the same S.A. These two model substrates thus empirically define a bioavailability envelope with $\mathrm{Fe}^{\prime}$ at the upper and FeDFB at the lower limit of iron bioavailability. This envelope provides a convenient framework to compare the relative bioavailabilities of various Fe substrates to eukaryotic phytoplankton and the Fe uptake abilities of different phytoplankton species. Compared with eukaryotic species, cyanobacteria have similar uptake constants for Fe' but lower ones for FeDFB. The unique relationship between the uptake rate constants and the S.A. of phytoplankton species suggests that the uptake rate constant of Fe-limited phytoplankton has reached a universal upper limit and provides insight into the underlying uptake mechanism.
\end{abstract}

The ISME Journal (2015) 9, 1003-1013; doi:10.1038/ismej.2014.199; published online 28 October 2014

\section{Introduction}

Iron is quantitatively the most important trace metal in photosynthetic microorganisms (Raven et al., 1999). Its significance within aquatics systems came to the fore with John Martin's pioneering work in High Nutrient Low Chlorophyll ocean regions (Martin and Fitzwater, 1988; Martin, 1990). The resulting Iron Hypothesis sparked great interest in iron as a key limiting nutrient for marine primary production and as an important factor in the global carbon cycle (Martin et al., 1991). Subsequent studies have shown that phototrophic microorganisms are Fe limited in vast regions of the world's oceans and some fresh water environments (Moore et al., 2001; McKay et al., 2004; Boyd et al., 2007; North et al., 2007).

At the circumneutral $\mathrm{pH}$ and oxic conditions that characterize such habitats, iron is poorly soluble

Correspondence: Y Shaked, The Interuniversity Institute for Marine Sciences in Eilat, PO Box 469, Coral Beach, Eilat 88103, Israel.

E-mail: yeala.shaked@mail.huji.ac.il

Received 29 May 2014; revised 22 August 2014; accepted 6 September 2014; published online 28 October 2014 and precipitates out of solution as ferric oxyhydroxide solids (Millero, 1998). Many open ocean waters and some freshwater systems are characterized by low dissolved iron $(<0.2 \mu \mathrm{m}$ size fraction) concentrations, often in the nanomolar or subnanomolar range (Johnson et al., 1997; McKay et al., 2004). A major fraction of this dissolved Fe pool, over $99 \%$, is complexed by organic ligands (Gledhill and van den Berg, 1994; Rue and Bruland, 1995; Wu and Luther, 1995; Gledhill and Buck, 2012). As a result, the dissolved unchelated inorganic iron, $\mathrm{Fe}^{\prime}$, comprising primarily $\mathrm{Fe}(\mathrm{OH})_{\mathrm{x}}$ complexes (Morel and Hering, 1993), is found at exceedingly low concentrations (Morel et al., 2008). Moreover, studies using ultrafiltration methods have found that colloids account for a significant fraction of the iron within the operationally defined dissolved $\mathrm{Fe}$ pool (Wu et al., 2001).

The least abundant form of dissolved iron, $\mathrm{Fe}^{\prime}$, has been found to be the most readily bioavailable to phytoplankton (Morel et al., 2008). This preference for $\mathrm{Fe}^{\prime}$ over other iron substrates is supported by theoretical calculations (Hudson and Morel, 1993) as well as direct uptake studies with laboratory cultures and field populations (see, for example, Maldonado 
et al., 2005; Shaked et al., 2005). Dissolved organically complexed iron is a heterogeneous Fe pool, the bioavailability of which depends in part on its chemical nature (Shaked and Lis, 2012). Lastly, the bioavailability of the colloidal and particulate $\mathrm{Fe}$ fractions is generally low and is a function of the thermodynamic stability and kinetic lability of these phases (Kuma and Matsunaga, 1995; Chen et al., 2003). Nevertheless, many studies have pointed to the importance of these fractions in replenishing the dissolved $\mathrm{Fe}$ pool via thermal, photochemical or ligand mediated dissolution (Sulzberger et al., 1989; Kraemer, 2004; Borer et al., 2005).

Iron bioavailability is not only a function of chemical speciation but also of phytoplankton physiology and Fe uptake mechanism. Studies in this field have focused on two major (but non-exclusive) pathways-reductive- and siderophore-mediated uptake. Reductive $\mathrm{Fe}$ uptake involves an integral reductive step before internalization of $\mathrm{Fe}$ via the cell plasma membrane. This prevalent pathway has been demonstrated in the uptake of $\mathrm{Fe}^{\prime}$ and organically bound $\mathrm{Fe}$ compounds in fresh water and marine prokaryotic and eukaryotic phytoplankton (Allnutt and Bonner, 1987; Jones et al., 1987; Eckhardt and Buckhout, 1998; Maldonado and Price, 2001; Lis and Shaked, 2009; Kranzler et al., 2011). Siderophoremediated $\mathrm{Fe}$ uptake involves direct transport of the ferric-siderophore complex into the cell where Fe is released from the chelating ligand. In comparison with the widespread reductive strategy, this mechanism characterizes fresh and brackish water prokaryotic phytoplankton (Hopkinson and Morel, 2009; Hopkinson and Barbeau, 2012).

The body of published studies on iron uptake by phytoplankton provides an extensive empirical foundation for exploring the factors governing iron bioavailability in aquatic environments. However, the synthesis of data into an encompassing view is often complicated by methodological differences between studies. Organism physiology and growth phase, iron substrate definition and concentration, $\mathrm{pH}$, illumination and temperature may all influence the experimental results and their interpretation, encumbering efforts at cross comparisons between studies. Here we attempt to resolve this difficulty by careful selection of iron uptake data covering experiments with a variety of Fe substrates and organisms under a range of conditions. Our analysis includes both original and published data. The results lend interesting insights into the factors that limit Fe uptake kinetics in phytoplankton and the underlying uptake mechanisms; they also provide a framework for examining the question of iron bioavailability in culture media and natural waters.

\section{Methods}

Analytical approach

In this contribution, we draw on original and previously published iron uptake rates to compile a database that covers a range of Fe substrates and phytoplankton species (Table 1). Uptake rates were derived from short-term as well as steady-state growth experiments. Short-term iron uptake $(\rho)$ is measured as the intracellular accumulation of radiolabeled $\mathrm{Fe}$ over time (typically $4 \mathrm{~h}$ to $8 \mathrm{~h}$ ). Steady-state iron uptake is calculated as the product of phytoplankton growth rate and intracellular iron concentration (equation 1):

$$
\rho_{\mathrm{ss}}=Q \cdot \mu
$$

where $\rho_{\mathrm{ss}}$ is the steady-state iron uptake rate in mol Fe per cell $\mathrm{h}^{-1}$; $Q$ is the intracellular iron concentration in mol Fe per cell (often called the Fe quota ) and $\mu$ is the specific growth rate in units of $\mathrm{h}^{-1}$.

The inclusion of diverse data sources introduces variability and experimental noise into the data set. One of our greatest challenges was that iron uptake rates were measured in different laboratories employing different experimental conditions and Fe substrate concentrations. To minimize these effects, stringent standards were applied in both data selection and analysis. We chose experiments conducted with iron-limited cells, that is, Fe concentrations in the growth medium were low enough to limit specific growth rate. In addition, the iron concentrations at which uptake rates were measured did not saturate cellular iron transporters and maximal $\mathrm{Fe}$ uptake rate (that is, $V_{\max }$ ) was not achieved (see Section 1 in Supplementary Appendix for further discussion). Under these conditions, $\mathrm{Fe}$ uptake rate is proportional to the $\mathrm{Fe}$ substrate concentration (equation 2):

$$
\rho=k_{\text {in }} \cdot[S]
$$

Where $\rho$ is the iron uptake rate in mol Fe per cell $\mathrm{h}^{-1} ; k_{\text {in }}$ is the uptake rate constant in $\mathrm{l}$ per cell $\mathrm{h}^{-1}$ and $[\mathrm{S}]$ is the Fe substrate concentration in the medium in $\mathrm{moll}^{-1}$. This type of analysis is suitable for both steady-state iron uptake experiments and short-term studies with cells preconditioned in Fe limiting growth medium. By virtue of its independence from substrate concentration, the uptake rate constant, $k_{\text {in }}$, facilitates the comparison of multiple iron substrates and organisms. Subsequent analysis of the data necessitated the calculation of cell surface area (S.A.) for each of the organisms. If available, surface areas were calculated from cell dimensions reported within the study in which iron uptake rates by a specific species were measured. If these were not provided, other literature reports on cell dimensions of this specie grown under Fe-limited conditions were averaged (see Section 2 in Supplementary Appendix for details).

\section{Data selection}

The data set analyzed here includes five major phytoplankton divisions, 15 species and $16 \mathrm{Fe}$ 
Table 1 A list of the phytoplankton species and Fe substrates included in our data set

\begin{tabular}{|c|c|c|c|}
\hline Division & Phytoplankon species & Fe substrates & References \\
\hline \multirow[t]{3}{*}{ Haptophytes } & Emiliania huxleyi (CCMP374; A1387) & $\mathrm{Fe}^{\prime}, \mathrm{FeDFB}$ & $\begin{array}{l}\text { (Sunda and Huntsman, 1995; Shi et al., } \\
\text { 2010, this study) }\end{array}$ \\
\hline & $\begin{array}{l}\text { Phaeocystis sp. (pouchetti, antarctica) } \\
\text { (CS243, NEPCC } 225, \text { SX9, AA1) }\end{array}$ & $\begin{array}{l}\mathrm{Fe}^{\prime}, \mathrm{FeDFB} \text {, ferrichrome (FC), } \\
\text { Southern Ocean natural ligands, } \\
\text { HBED, porphyrin,gallocatechin } \\
\text { (CAT), saccharides }\end{array}$ & $\begin{array}{l}\text { (Hassler and Schoemann, 2009; Lane } \\
\text { et al., 2009; Strzepek et al., 2011) }\end{array}$ \\
\hline & $\begin{array}{l}\text { Chrysochromulina polylepis } \\
\text { (NEPCC242) }\end{array}$ & $\mathrm{Fe}^{\prime}$ & (Lane et al., 2009) \\
\hline \multirow[t]{7}{*}{ Diatoms } & $\begin{array}{l}\text { Pseudo-nitzschia sp. (for example, } \\
\text { turgidula, heimii, multiseries) } \\
\text { (UBC103, UBC403, UBC303, Orø13) }\end{array}$ & $\mathrm{Fe}^{\prime}$ & (Marchetti et al., 2006) \\
\hline & Thalassiosira (oceanica, antarctica, & $\mathrm{Fe}^{\prime}, \mathrm{FeDFB}$, Southern Ocean natural & (Sunda and Huntsman, 1995; \\
\hline & & & \\
\hline & CCMP1003, NEPCC58) & $\begin{array}{l}\text { phyrin, humic acid, ferrichrome (FC), } \\
\text { DFE, Enterobactin, Aerobactin, }\end{array}$ & $\begin{array}{l}\text { Shaked et al., 2004; Kustka et al., 2005; } \\
\text { Marchetti et al., 2006; Kustka et al., }\end{array}$ \\
\hline & & Azotochelin & $\begin{array}{l}\text { 2007; Chen and Wang, 2008; Hassler } \\
\text { and Schoemann, 2009; Lane et al., 2009; } \\
\text { Shi et al., 2010; Strzepek et al., 2011) }\end{array}$ \\
\hline & $\begin{array}{l}\text { Phaeodactylum tricornutum } \\
\text { (CCMP2557, CCMP630) }\end{array}$ & $\mathrm{Fe}^{\prime}$ & (Kustka et al., 2007; Shi et al., 2010) \\
\hline & Chaetoceros spp (CS624) & $\begin{array}{l}\text { FeDFB, Southern Ocean, HBED, } \\
\text { porphyrin, saccharide,gallocatechin } \\
\text { (CAT) }\end{array}$ & (Hassler and Schoemann, 2009) \\
\hline Dynophytes & Prorocentrum spp (minimum, micans) & $\mathrm{Fe}^{\prime}$ & $\begin{array}{l}\text { (Sunda and Huntsman, 1995; Sunda } \\
\text { and Huntsman, 1997) }\end{array}$ \\
\hline \multirow[t]{2}{*}{ Heterokonts } & Pelagomonas calceolate (CCMP1214) & $\mathrm{Fe}^{\prime}$ & (Sunda and Huntsman, 1995) \\
\hline & Nannochloropsis oculata (CCAP 251/5) & $\mathrm{Fe}^{\prime}, \mathrm{FeDFB}, \mathrm{FeAB}$ & (this study) \\
\hline \multirow[t]{5}{*}{ Cyanobacteria } & Prochlorococcus spp (MED4, MIT9319) & $\mathrm{Fe}^{\prime}, \mathrm{FeDFB}$ & (Thompson, 2009, this study) \\
\hline & $\begin{array}{l}\text { Synechococcus spp (WH7803; } \\
\text { WH8102; CCMP1183; PCC7002) }\end{array}$ & $\mathrm{Fe}^{\prime}, \mathrm{FeDFB}$ & (this study) \\
\hline & Syenchosystis sp (PCC6803) & $\mathrm{Fe}^{\prime}, \mathrm{FeDFB}$ & (Kranzler et al., 2011) \\
\hline & Trichodesmium erythraeum (IMS101) & $\mathrm{Fe}^{\prime}$ & (this study) \\
\hline & Anabeana sp (UTEX 2576) & $\mathrm{Fe}^{\prime}, \mathrm{FeDFB}$ & (this study) \\
\hline
\end{tabular}

substrates collected from 18 distinct studies (Table 1). Published studies were selected on the basis of a set of biological and chemical criteria outlined in Table 2. Further details on the data set are provided in Section 2 of the Supplementary Appendix and Supplementary Tables S1-S5. We have also included original data for several phytoplankton species and Fe substrates. The methods employed in the generation of original data (trace metal clean methods, phytoplankton growth and iron limitation and short-term ${ }^{55} \mathrm{Fe}$ uptake experiments) are outlined in Section 3 of the Supplementary Appendix.

Two commonly used Fe substrates form the backbone of our analysis: inorganic unchelated iron $\left(\mathrm{Fe}^{\prime}\right)$ in media buffered with an excess of EDTA and Fe chelated by the siderophore desferri-ferrioxamine B (DFB). These substrates were chosen because they are chemically well defined and each constitutes a single bioavailable iron substrate. The synthetic chelator EDTA is commonly used to buffer constant and easily calculable $\mathrm{Fe}^{\prime}$ concentrations (Sunda et al., 2005). FeEDTA itself is not bioavailable and the only bioavailable iron substrate in this system is $\mathrm{Fe}^{\prime}$ (Shaked et al., 2005). While FeEDTA is photolabile, this process can be quantified and the $\mathrm{Fe}^{\prime}$ concentrations in an illuminated growth medium can be precisely calculated. The $\mathrm{Fe}^{\prime}$ concentrations in the different experimental media were calculated according to Sunda et al. (2005) as well as using Visual Minteq software (Gustafsson, 2010). FeDFB is an extremely stable ferric-siderophore complex with $\log K_{\mathrm{FeL}}^{\mathrm{Fe}}=16.5$ (Hudson et al., 1992) and when iron is complexed to a slight excess of DFB, Fe' concentrations are negligible. In addition, the FeDFB complex is not photosensitive and light does not affect Fe speciation. Thus in these experiments FeDFB is the only substrate for Fe uptake.

\section{Results}

Uptake of unchelated iron $\left(F e^{\prime}\right)$

We first examined the uptake kinetics of inorganic iron $\left(\mathrm{Fe}^{\prime}\right)$ in EDTA-buffered media. The data set includes both steady-state (growth) and short-term iron uptake rates of Fe-limited phytoplankton (Table 1). It contains both prokaryotic and eukaryotic phytoplankton, encompassing 15 species and 28 strains isolated from a range of aquatic environments (fresh, brackish and marine waters) and grown under different conditions, including 
Table 2 Criteria guiding data collection

Data selection criterion
Fe status of cells-only iron-limited cells
Fe substrates-preferably chemically defined substrates,
where only one Fe species is available for uptake

where only one Fe species is available for uptake

Fe substrate concentrations-sub-saturating with respect to cellular Fe uptake sites

Growth phase-only exponentially growing cells

Cell density-low cell density to avoid changes in $\mathrm{Fe}$ concentration and speciation during the uptake experiments

Extracellular Fe washed before measurements

Minimal excess free ligand (for siderophore-bound Fe uptake). uptake mechanisms (Shaked et al., 2005). Therefore, uptake experiments with strong Fe complexes (not including EDTA) with minimal excess ligand were selected (Fe:L < 1:5)

These criteria apply to both steady-state and short-term Fe uptake data.

different growth media, temperatures and light regimes. When uptake rates are plotted as a function of total Fe concentration in the media on a log-log graph, the data points are widely scattered (Figure 1a). As $\mathrm{Fe}^{\prime}$ rather than FeEDTA is the substrate for uptake, this scatter is slightly reduced when the same uptake rates are plotted against the calculated concentrations of $\mathrm{Fe}^{\prime}$ present in the experiment (Figure 1b). The high gray points outlined by stars in Figures $1 \mathrm{a}$ and $\mathrm{b}$ correspond to larger cells, whereas the lower black points outlined by circles correspond to smaller cells.

Sunda and Huntsman (1995) showed that $\mathrm{Fe}^{\prime}$ uptake rate is proportional to cell S.A. in several phytoplankton species. We thus plotted the uptake rate constants, $k_{\text {in }}$ (obtained by dividing the uptake rates, $\rho$, by the $\mathrm{Fe}^{\prime}$ concentrations; equation (2)) against cell S.A. (Figure 1c). This graph reveals a very high correlation between the uptake rate constant and the S.A. across 104 individual experiments involving both short-term and steady-state measurements of uptake kinetics $\left(r^{2}=0.944\right.$ for best the linear fit of $k_{\text {in }}$ vs S.A.- - not on a log scale, see Section 4 of Supplementary Appendix and Supplementary Figure S2). In addition, the slope of the linear fit on the log-log graph is negligibly different from unity. The trend line in Figure $1 \mathrm{~b}$ has been forced through the origin $\left(r^{2}=0.942\right)$, corresponding to a linear fit with a slope of 1 on the log-log graph. In other words, the Fe uptake rates of taxonomically diverse phytoplankton in the presence of the same $\mathrm{Fe}^{\prime}$ concentration are directly proportional to their S.A. and the experimental procedures are accurate and consistent enough to reveal this relationship.

The uptake rates of iron bound to the hydroxamate siderophore DFB were analyzed in a similar manner to the $\mathrm{Fe}^{\prime}$ data (Figure 2). Due to the high stability of the FeDFB complex and the slight excess of DFB over iron in these experiments, all the iron in the experiments is present as FeDFB. This smaller data set also shows some scatter when uptake rates are plotted as a function of FeDFB concentration (Figure 2a). However, when uptake rates are converted to uptake rate constants (obtained by dividing the uptake rate, $\rho$, by the FeDFB concentration) and plotted against S.A, a strong linear correlation between the two is apparent (Figure 2b). Similar to the $\mathrm{Fe}^{\prime}$ data, the slope on the log-log graph is negligibly different from unity $\left(r^{2}=0.90\right.$ for the best fit, and $r^{2}=0.89$ when the fit of $k_{\text {in }}$ versus S.A. is forced through the origin, see Section 4 of Supplementary Appendix and Supplementary Figure S3) demonstrating a direct proportionality between the uptake rate constant, $k_{\mathrm{in}}$, and cell S.A. in both short-term and steady-state Fe uptake data. 
a

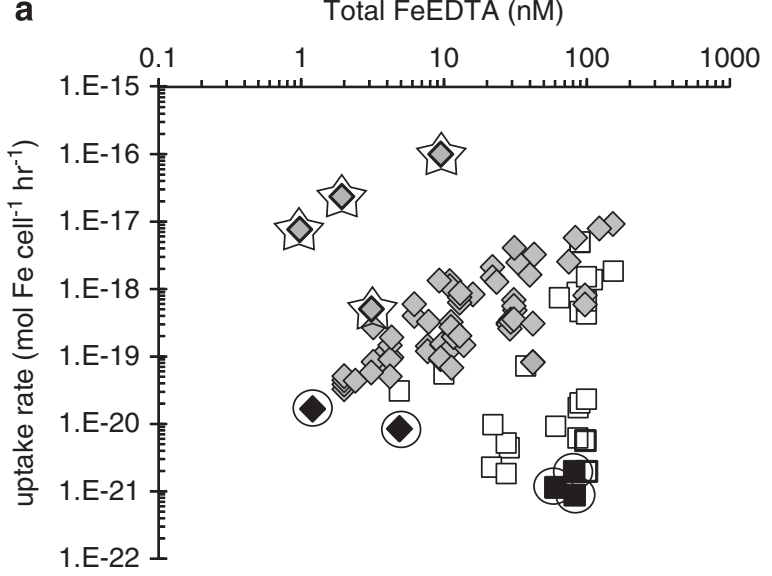

b

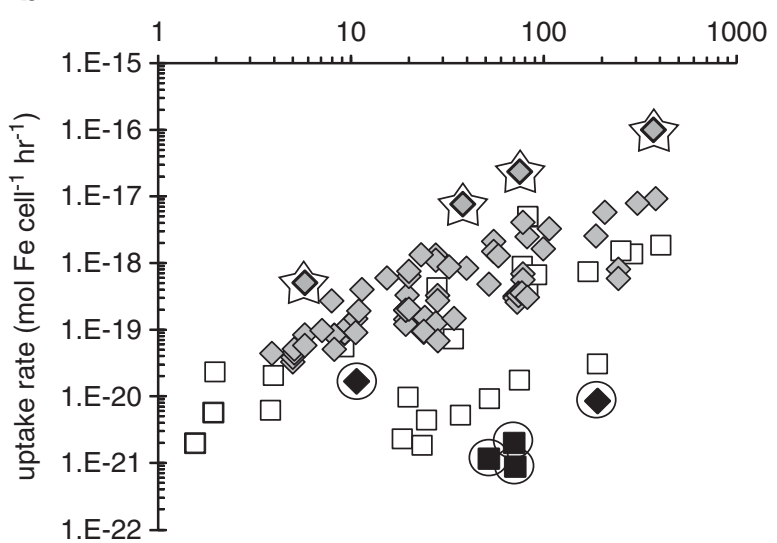

C

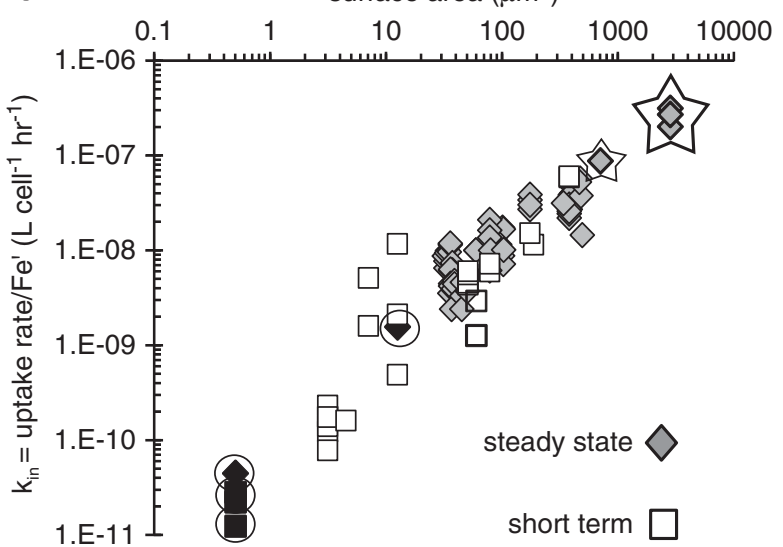

Figure $1 \mathrm{Fe}$ ' uptake rates of Fe-limited phytoplankton within an FeEDTA system. Each data point represents a single rate measurement derived from either short-term radioisotope (diamonds) or steady-state growth (squares) experiments. To encompass the breadth of Fe concentrations and uptake rates, both $x$ and $y$ axes are in log scale. Data points for the largest cells are outlined by stars, while data points representing the smallest cells are black and outlined by circles. (a) Cellular iron uptake rate (mol Fe per cell $\mathrm{h}^{-1}$ ) as a function of FeEDTA concentration (nм). (b) Iron uptake rate as a function of unchelated inorganic iron, $\mathrm{Fe}^{\prime}$ (рм). (c) Uptake rate normalized to $\mathrm{Fe}^{\prime}$ concentration $\left(\mathrm{l}\right.$ per cell $\left.\mathrm{h}^{-1}\right)$ as a function of cell S.A. $\left(\mu \mathrm{m}^{2}\right)$.
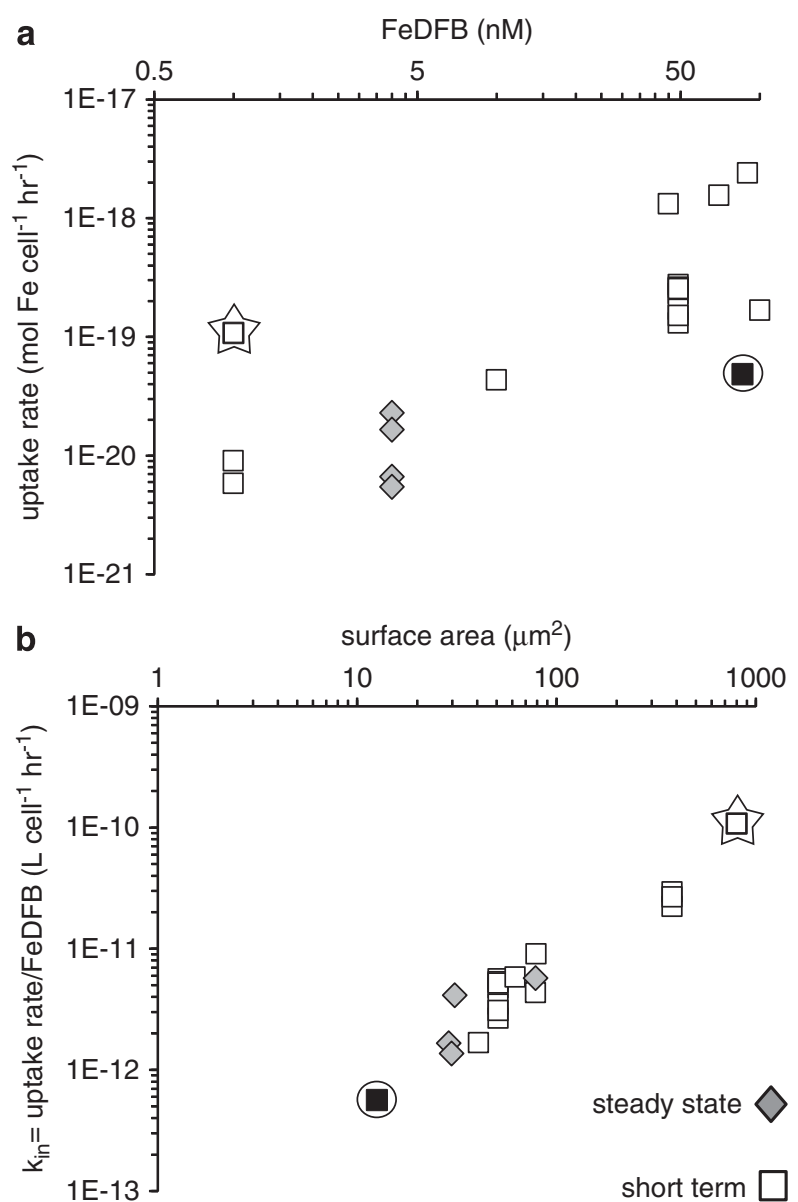

Figure 2 FeDFB uptake by iron-limited phytoplankton. Each data point represents the result of a single experiment. Short-term and steady-state growth measurements are indicated by diamonds and squares respectively. Data points for the largest cells are outlined by stars, while data points representing the smallest cells are black and outlined by circles. Note that $x$ and $y$ axes are in log scale. (a) Fe uptake rate as a function of FeDFB concentration. Even in the presence of slight excess ligand relative to iron, $\mathrm{Fe}^{\prime}$ concentrations in this experimental system are negligible and the sole substrate for uptake is FeDFB. (b) Uptake rate normalized to FeDFB $\left(1\right.$ per cell $\left.\mathrm{h}^{-1}\right)$ as a function of cell S.A. $\left(\mu \mathrm{m}^{2}\right)$.

The bioavailability envelope

From the large data set presented in Figures 1 and 2, we compiled the $\mathrm{Fe}^{\prime}$ and FeDFB uptake data of Fe-limited eukaryotic phytoplankton into a single figure (Figure 3). Multiple uptake data reported for a single organism in a specific study were averaged and various symbols denote the different phylogenetic lineages. The positions of the linear fits for $\mathrm{Fe}^{\prime}$ and FeDFB differ by three orders of magnitude, indicating that, for the same S.A., eukaryotic phytoplankton take up $\mathrm{Fe}^{\prime} 1000$-fold faster than FeDFB. As seen in Figures $4 \mathrm{a}$ and $\mathrm{b}$, the other substrates we examined, be they model Fe compounds or chemically complex substrates from natural environments, fall mostly within the boundaries defined by $\mathrm{Fe}^{\prime}$ and $\mathrm{FeDFB}$ trend lines. For a given S.A., no $\mathrm{Fe}$ substrate was taken up significantly faster than $\mathrm{Fe}^{\prime}$ nor slower than FeDFB. 


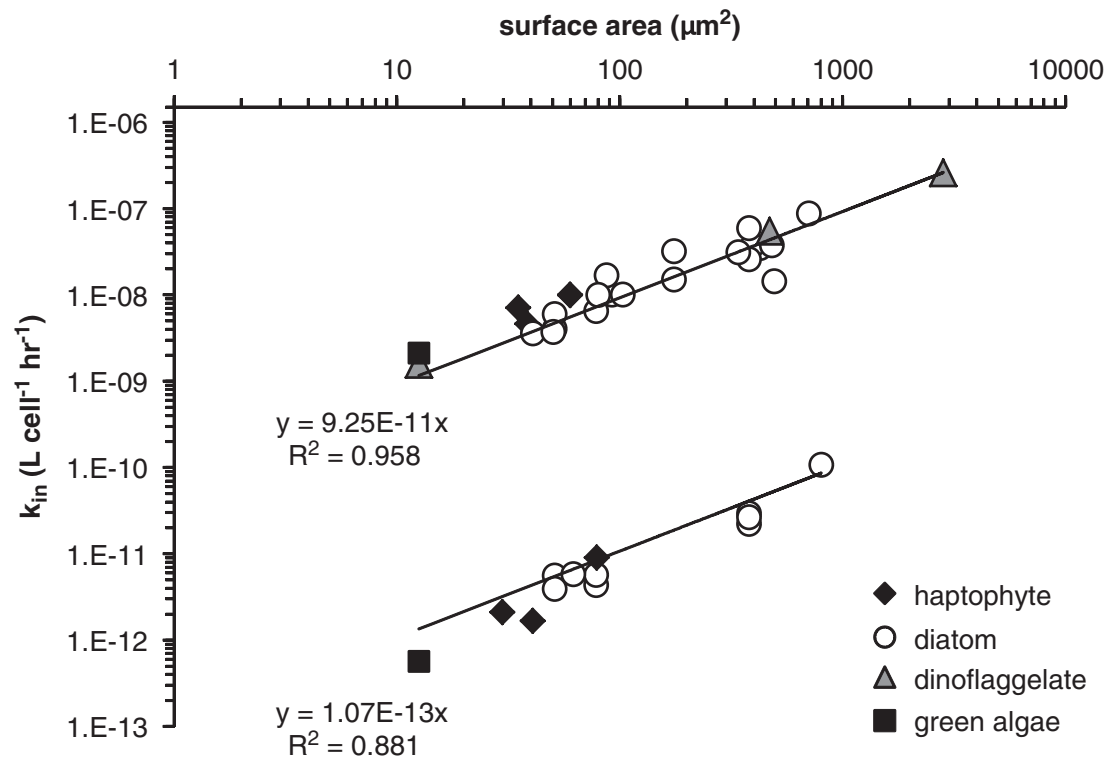

Figure 3 The apparent iron uptake rate constant $\left(k_{\text {in }}\right.$ in units of 1 per cell $\left.h^{-1}\right)$ as a function of S.A. for Fe-limited eukaryotic phytoplankton. Two iron substrates are shown- $\mathrm{Fe}^{\prime}$ and FeDFB. Each data point on the graph represents an averaged value of the uptake rate constants calculated for a single organism from a single study. Various phytoplankton taxa are represented by different symbols.

a

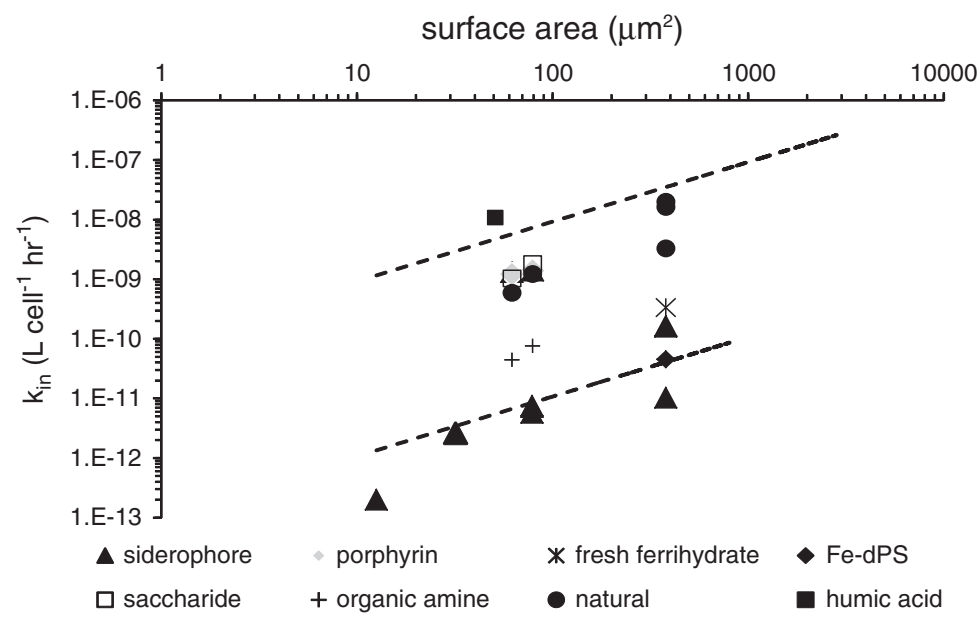

b

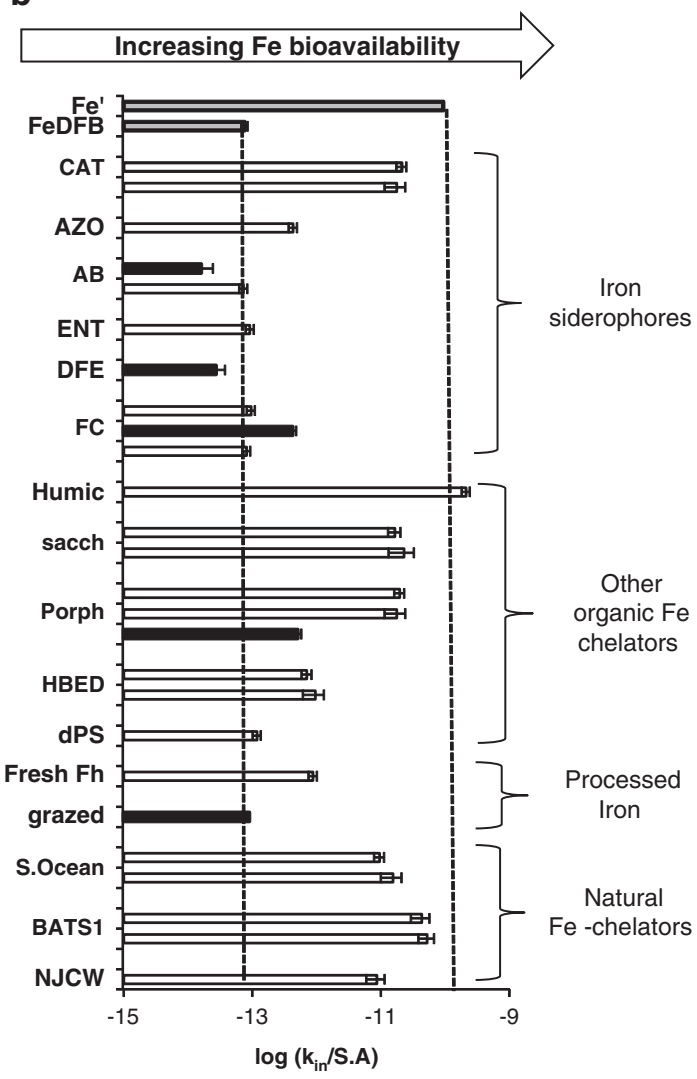

Figure 4 Comparing Fe substrate bioavailability to iron-limited eukaryotic phytoplankton within the context of a 'bioavailability envelope'. The envelope's boundaries are delineated by dashed lines, with unchelated inorganic iron ( $\left.\mathrm{Fe}^{\prime}\right)$ as its upper boundary and FeDFB at its lower boundary. (a). Fe substrate bioavailability to different organisms. Each data point is a measurement from a different study. Details regarding organism identity can be found in Supplementary Table S3. Error bars have been omitted for clarity. (b). A bar graph representation of relative bioavailability. Each bar for a given compound represents a different organism. We define substrate bioavailability as the S.A.-normalized uptake rate constant $\left(\frac{\text { Uptakerate }}{\mathrm{Fe}-\text { substrate. } \mathrm{SA}}=\frac{k_{\text {in }}}{\mathrm{SA}}\right)$. Black bars represent experiments conducted in the dark, while white bars represent experiments conducted in the light. 


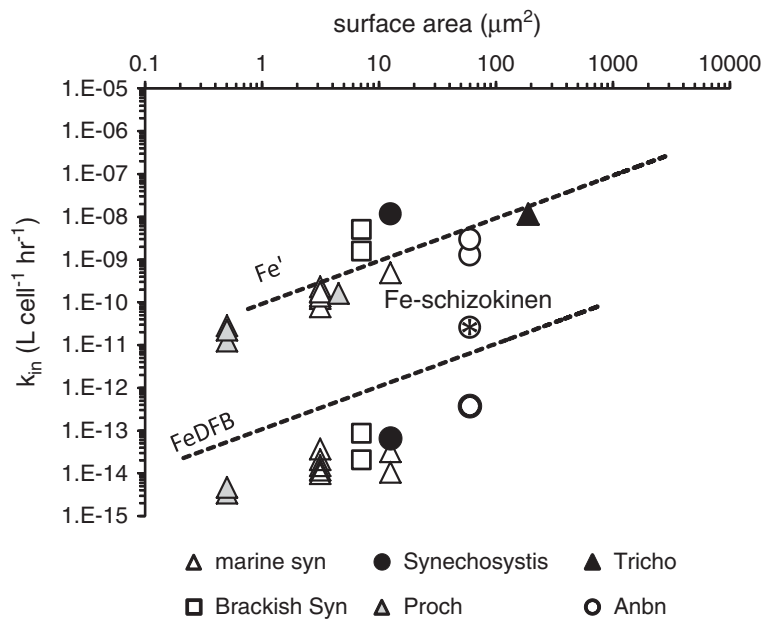

Figure 5 The uptake rate constants $\left(k_{\text {in }}\right)$ for $\mathrm{Fe}^{\prime}$ and FeDFB uptake by iron-limited cyanobacteria. The data is presented within the bioavailability envelope based on the $\mathrm{Fe}^{\prime}$ and FeDFB uptake of iron-limited eukaryotic phytoplankton (dashed trend lines). Each data point represents a value taken from a different study. A single point of Fe-schizokinen uptake by Anabaena (starred circle) is included for comparison. The symbols indicate different strains: marine Synechococcus (white triangles), brackish Synechococcus (white squares), Synechocystis (black circles), Prochlorococcus (gray triangles), Trichodesmium (black triangles) and Anabaena (white circles).

The large number of studies evaluating $\mathrm{Fe}^{\prime}$ and FeDFB uptake by Fe-limited eukaryotic phytoplankton thus define a 'bioavailability envelope' with an upper boundary corresponding to $\mathrm{Fe}^{\prime}$ uptake and a lower boundary defined by FeDFB uptake. The compounds lying closer to the FeDFB trend line are octahedrally coordinated Fe-siderophore complexes-iron bound to aerobactin, enterobactin, ferrioxamine $\mathrm{E}$ and ferrichrome-and ferrihydrite sequestered in the iron storage protein Dps (Fe-Dps). Those lying closer to the $\mathrm{Fe}^{\prime}$ trend are Fe-saccharide, Fe-humic acid and Fe-porphyrin complexes. Going from model compounds to iron bound to natural ligands from the Western Atlantic and Southern Ocean, we find that the corresponding uptake constants plot closer to the $\mathrm{Fe}^{\prime}$ trend line than to FeDFB (Figure 4).

\section{Fe uptake by cyanobacteria}

In addition to providing a convenient means of comparing the bioavailabilities of Fe substrates to eukaryotic phytoplankton, the $k_{\text {in }}$ versus S.A. graph can also be used to compare the bioavailabilities of the same substrates to different phytoplankton taxa. We found a remarkable similarity between cyanobacterial $\mathrm{Fe}^{\prime}$ uptake data and that of eukaryotes, with the cyanobacterial data points falling largely along the eukaryotic trend (Figure 5). This similarity in the $\mathrm{Fe}^{\prime}$ uptake data for prokaryotic and eukaryotic phytoplankton is independent of the habitat from which cyanobacterial strains were isolated or the composition of their culture media (which are markedly different from the eukaryotic culture medium in ionic strength and nutrient composition). In contrast, the FeDFB uptake constants of cyanobacteria are about 20-fold lower than those of the eukaryotes, although interestingly they still show a rough proportionality to the S.A. of the organisms (Figure 5). Fe-schizokinen uptake by Felimited Anabaena was also included in this analysis as a reference for endogenous siderophore uptake by siderophore producing cyanobacteria. The corresponding point (starred circle, Figure 5) is one order of magnitude above the trend line for FeDFB uptake by cyanobacteria.

\section{Discussion}

What mechanisms are responsible for the similarity in S.A.-normalized Fe uptake rates across phytoplankton species for both $\mathrm{Fe}^{\prime}$ and $\mathrm{FeDFB}$ ?

The most striking empirical observation emerging from our study is that when grown under Fe limitation, all eukaryotic phytoplankton species have essentially identical uptake rate constants for $\mathrm{Fe}^{\prime}$ and FeDFB when normalized to S.A. Such a similarity suggests that iron in aquatic environments has exerted significant selective pressure on phytoplankton to evolve Fe uptake mechanisms that operate at the optimal efficiency permitted by fundamental physical, chemical or biochemical factors (Hudson and Morel, 1990; Sunda and Huntsman, 1995). If this is so, the results of our analysis may provide insight into the factors that limit iron uptake rates in phytoplankton.

The uptake of Fe by a cell first requires molecular diffusion of the Fe substrate from the bulk medium to the cell surface. The diffusive flux is proportional to the (equivalent) radius, $r$, of the cell and thus cannot explain our results showing proportionality of $\mathrm{Fe}$ uptake to the S.A., that is, to $r^{2}$. Further calculations show that the diffusion of $\mathrm{Fe}^{\prime}$ or $\mathrm{FeDFB}$ to cell surfaces is much faster than the measured uptake rates unless the cells are very large $(r \sim 35$ $\mu \mathrm{m})$, larger than all the species included in our data set (see Section 5 in of Supplementary Appendix and Supplementary Figures S4 and S5).

The proportionality of the uptake rate constant, $k_{\text {in }}$, to S.A. demonstrated in Figures $1-3$ is most simply explained by a limit on membrane components involved in Fe uptake. The number of Fe uptake components at the surface of a cell must be limited by their size and the available membrane area, which is itself restricted by the space occupied by all other membrane components necessary for cellular functions and the integrity of the lipid bilayer. The net result should be an uptake rate that is proportional to S.A. and roughly the same S.A. normalized $k_{\text {in }}$ for all species, provided that they employ a similar iron uptake mechanism. 
A growing body of evidence points to the prevalence of reductive iron uptake in the acquisition of $\mathrm{Fe}^{\prime}$ and organically bound iron species such as FeDFB by both fresh water and marine phytoplankton (Allnutt and Bonner, 1987; Jones et al., 1987; Eckhardt and Buckhout, 1998; Maldonado and Price, 2001; Shaked et al., 2005; Kustka et al., 2007; Kranzler et al., 2011; Shaked and Lis, 2012). The mechanism of $\mathrm{Fe}(\mathrm{III})$ uptake by phytoplankton appears to be a two-step process: iron reduction at the cell surface followed by its transport across the cell membrane. As a result, two types of iron uptake components in the membrane of eukaryotic phytoplankton are involved in Fe(III) uptake: Fe transporters (ferrioxidase-permeases) and (transmembrane) reductases (Maldonado and Price, 2001; Maldonado et al., 2006; Kustka et al., 2007). A maximum areal concentration of either could be responsible for the observed proportionality between $k_{\mathrm{in}}$ and the S.A. of cells.

An upper limit to Fe uptake rate resulting from a maximum concentration of transport ligands in the membrane of phytoplankton was invoked in early work (Hudson and Morel, 1990; Sunda and Huntsman, 1995), before it was recognized that reduction of $\mathrm{Fe}(\mathrm{III})$ normally precedes uptake (Maldonado and Price, 2001; Shaked et al., 2005; Maldonado et al., 2006). Nevertheless, the uptake could be limited by the rate of reaction of $\mathrm{Fe}(\mathrm{II})$ with transporters following Fe(III) reduction at the surface. This would require that the $\mathrm{Fe}(\mathrm{II})$ concentration at the surface, Fe(II)s (Shaked et al., 2005), be maintained by a balance between reduction and losses, both faster than the uptake itself. Losses of Fe(II)s may occur because of oxidation, diffusion to the bulk solution or complexation by a competing Fe(II) ligand as demonstrated experimentally (Shaked et al., 2005). In that case, transmembrane transport becomes the limiting step and the proportionality of $k_{\text {in }}$ to S.A. then results from the maximum areal concentration of transporters in the membrane.

Estimation of reduction from ferrozine binding rates shows that reduction rates and Fe uptake rates are on the same order of magnitude (Shaked et al., 2004), suggesting that these two processes are in fact coupled and that $\mathrm{Fe}(\mathrm{II}) \mathrm{s}$ loss is not substantial. If losses are small compared with transport across the membrane, then Fe(II)s is maintained chiefly by a balance between reduction and uptake, and the limiting step would be the rate of reduction of Fe(III) substrates. In that case, a proportionality of $k_{\text {in }}$ to cell S.A. could be determined by the maximum possible number of membrane reductases per area of cell membrane. This explanation would fit well with the observation of much lower $k_{\text {in }}$ for FeDFB than for $\mathrm{Fe}^{\prime}$, the uptake of which is presumably enabled by the same reductases and transporters. The much slower uptake of FeDFB compared with $\mathrm{Fe}^{\prime}$ would result from the slower reduction of chelated than unchelated Fe(III), as discussed below.
Comparing the bioavailability of different iron substrates

The 'bioavailability envelope' outlined by the $\mathrm{Fe}^{\prime}$ and FeDFB data is convenient for visualizing and comparing the bioavailabilities of various $\mathrm{Fe}$ substrates. The relative bioavailabilities of different $\mathrm{Fe}$ complexes, inferred from the $k_{\text {in }}$ constant, must ultimately depend on the reactivity of the bound $\mathrm{Fe}(\mathrm{III})$ with the cell as well as the lability of the ferric complex and concentration of $\mathrm{Fe}^{\prime}$ in the medium. Thus, for example, in the case of $\mathrm{Fe}^{\prime}$ in an EDTA-buffered system, FeEDTA itself is biologically non-reactive and the $k_{\text {in }}$ calculated for such a system reflects $\mathrm{Fe}^{\prime}$ only. On the other extreme, the FeDFB complex is extremely stable and $\mathrm{Fe}^{\prime}$ is negligible. The $k_{\text {in }}$ in this case reflects only organically bound iron in the form of FeDFB. Many Fe substrates, however, fall between these two extremes. Therefore, caution should be exercised in the interpretation of the $k_{\text {in }}$ constant. If the uptake medium contains weak and/or photolabile Fe complexes, then even when the ligand concentration exceeds iron concentration, a significant amount of unchelated $\mathrm{Fe}$ may be present (note that most experiments reported in Figure 4 were conducted in the light). In such instances, the calculated $k_{\text {in }}$ reflects a mixed substrate pool including both complexed iron (FeL) and uncomplexed iron $\left(\mathrm{Fe}^{\prime}\right)$. This is very likely the case with ligands such as porphyrins, humic acids and saccharides, which all show high $\mathrm{Fe}$ bioavailability (Figure 4). In this situation, the uptake rate constant $k_{\text {in }}$ does not represent a true kinetic parameter but it nonetheless provides a useful measure of bioavailability of the total Fe pool in the presence of such ligands. At the other extreme, not all the iron in the experimental medium may be truly dissolved and thus able to diffuse to the cell surface and react with iron transport ligands at the cell membrane. This is the case for freshly precipitated ferrihydrite, grazed iron and ferrihydrite sequestered within the iron storage protein Dps (Figure 4). In this instance, the parameter $k_{\text {in }}$ again provides an overall measure of bioavailability, although the proportionality between uptake rate and total Fe substrate concentration may only obtain over a small concentration range. Even in the presence of strong ligands, the uptake rate may not be proportional to the substrate concentration if the strong ligand is present in large excess. As shown by Shaked et al. (2005), a ligand in large excess can compete with uptake molecules for the Fe(II) produced at the surface and decrease the uptake rate.

Given the prevalence of reduction as an Fe uptake strategy amongst eukaryotic phytoplankton (see discussion above), the bioavailability of a given $\mathrm{Fe}$ substrate must depend on its reducibility. When bound in an extremely stable octahedral coordination with an hexadentate siderophore like FeDFB, $\mathrm{Fe}(\mathrm{III})$ is much more difficult to reduce than $\mathrm{Fe}(\mathrm{III})$ coordinated only to water and hydroxide 
(that is, $\mathrm{Fe}^{\prime}$ ). This likely accounts for the thousand fold difference in the uptake rate constants between $\mathrm{Fe}^{\prime}$ and FeDFB (Figure 3). Although the current knowledge on cell surface reductases in eukaryotic phytoplankton is limited (Kustka et al., 2007; Allen et al., 2008), it seems likely that both $\mathrm{Fe}^{\prime}$ and $\mathrm{FeDFB}$ are reduced by the same surface reductase. Iron substrates that share chemical characteristics with FeDFB exhibit similarly low bioavailabilities (Figure 4). Aerobactin, enterobactin, ferrioxamine E and ferrichrome are all, like DFB, hexadentate siderophores and the very low redox potential of the Fe(III) bound within these ligands makes it difficult to reduce (Pierre et al., 2002). Siderophores that do not behave in a similar manner are characterized by a lower denticity and coordination number with regards to ferric iron and thus potentially higher 'reducibility'. These include the bidentate gallotochetechin (CAT) and tetradentate azotochelin (AZO).

How do Fe uptake rates of cyanobacteria compare with those of eukaryotes?

The surprising similarity of S.A. normalized $\mathrm{Fe}^{\prime}$ uptake between cyanobacteria and eukaryotic phytoplankton (Figure 5) implies that similar factors may be responsible for the upper limit on Fe uptake in both. Indeed, recent studies support the presence of a reductive step in $\mathrm{Fe}^{\prime}$ uptake by Fe-limited cyanobacteria (Salmon et al., 2006; Lis and Shaked, 2009; Kranzler et al., 2011; Kranzler et al., 2014). This is consistent with the idea that the upper limit to iron uptake is fixed by the same maximum in the rate of $\mathrm{Fe}$ (III) reduction per S.A. as in eukaryotic phytoplankton. In contrast, the uptake rate of FeDFB in cyanobacteria is considerably slower than in eukaryotes of the same size (Figure 5). Interestingly, FeDFB uptake rates still appear to be proportional to cell S.A.. This observation is independent of the organism's ability to produce and/or transport siderophores. Out of the nine cyanobacterial strains analyzed here, two are siderophore producers (Anabaena UTEX 2576 and Synechococcus PCC7002) and three have known ferric-siderophore transporters (Anabaena UTEX 2576, Synechosystis PCC6803 and Synechococcus PCC7002). However, DFB is neither produced by any of these cyanobacterial strains nor is it structurally similar to their endogenous siderophores. Endogenous $\mathrm{Fe}$-siderophore transport is in fact faster than FeDFB uptake as can be seen in the case of $\mathrm{Fe}$-schizokinen transport by Anabaena UTEX 2576 (starred circle, Figure 5). Thus, FeDFB uptake probably depends on the reduction of Fe(III) such that less effective reductases in cyanobacteria than those in eukaryotes could conceivably be responsible for the lower FeDFB uptake rate. A more likely explanation stems from the necessity for Fe(III) substrates to first penetrate through the outer membrane of these Gram-negative bacteria before undergoing reduction in the periplasmic space (Kranzler et al., 2014). The bulky nature of the
FeDFB complex may prevent or severely impede its passage through outer membrane porins, a process whose upper limit is necessarily proportional to the S.A. of the cells. In contrast, transport of $\mathrm{Fe}-$ schizokinen by Anabaena spp. occurs via specific ferric-siderophore transporters, allowing smooth passage across the outer membrane (Lammers and Sanders-Loehr, 1982).

\section{Implications for Fe uptake in natural waters}

Although laboratory based, the bioavailability envelope provides an empirical framework within which to assess iron availability in natural aquatic environments. The overwhelming majority ( $>99 \%$ ) of the dissolved iron in the ocean is complexed by strong but poorly characterized organic ligands (Gledhill and Buck, 2012). Nonetheless, the $k_{\text {in }}$ of these Fe substrates falls closer to the $\mathrm{Fe}^{\prime}$ than the FeDFB trend line (Figure 4). One explanation for this relatively high bioavailability of naturally occurring Fe(III) complexes is their photolability and subsequent increase of the transient $\mathrm{Fe}^{\prime}$ pool. Maldonado et al. (2005) showed that the uptake rates of naturally occurring Fe substrates by in situ phytoplankton assemblages are significantly faster in the light than in the dark. In addition, Barbeau et al. (2001) proposed that photolabile Fe-siderophore complexes enhance the pool of reactive iron species in marine environments, thereby enhancing overall iron bioavailability. Another possible explanation for the relatively high bioavailability of naturally occurring iron is the action of weak ligands which may enhance metal uptake in the presence of strong chelators as has been shown recently for $\mathrm{Zn}$ (Aristilde et al., 2012). These two processes may act individually or in synergy, resulting in enhanced Fe bioavailability in natural environments.

The unique relationship observed empirically between the uptake rate constants for $\mathrm{Fe}^{\prime}$ and the S.A. of many phytoplankton species suggests that the maximum uptake rate of Fe-limited phytoplankton has reached a universal upper limit. If phytoplankton cannot further increase uptake rates, a competitive advantage in Fe-limited waters must be gained through alternative means. This is commonly achieved through a decrease in cell size and/or a decrease in cellular $\mathrm{Fe}$ requirements. In general, smaller cells have a clear advantage in meeting cellular iron demands thanks to their high S.A. to volume ratios. Accordingly, in situ observations show that Fe-limited ocean regions are dominated by smaller phytoplankton size classes (see, for example, Gervais et al., 2002). However, small cell size may not always prevent iron stress. Cyanobacterial iron allocation is less efficient than that of eukaryotes as evidenced by their disproportionally large $\mathrm{Fe}$ :C ratios (Brand, 1991). As a result, open ocean cyanobacteria such as Prochlorococcus may experience Fe limitation despite their small size (Mann and Chisholm, 2000). On the other end of the size spectrum, very large cells, such as certain diatom species in the 
Southern Ocean, may also be an exception in that they are able to maintain relatively high growth rates despite very low cellular Fe quotas (Strzepek et al., 2011); the underlying physiology of this mechanism being unknown as yet. Less conventional strategies that may confer an advantage in iron-limited waters are symbiotic relationships with bacteria (Amin et al., 2009) or the utilization of iron from the colloidal or particulate fraction (Nodwell and Price, 2001; Rubin et al., 2011).

\section{Conflict of Interest}

The authors declare no conflict of interest.

\section{Acknowledgements}

We wish to thank A Rose, B Lazar and Y Rosenberg for their insights and assistance during the preparation of this manuscript as well as the reviewers and editor for their valuable comments. This work was supported in part by the Israel USA Binational Science Foundation grant 2008097 awarded to FMMM and YS, a grant the US National Science Foundation awarded to FMMM, grant 806/11 from the Israeli Science Foundation awarded to NK and the Assemble FP7 research grant awarded to HL.

\section{References}

Allen AE, LaRoche J, Maheswari U, Lommer M, Schauer N, Lopez PJ et al. (2008). Whole-cell response of the pennate diatom Phaeodactylum tricornutum to iron starvation. Proc Natl Acad Sci USA 105: 10438-10443.

Allnutt FCT, Bonner WD. (1987). Evaluation of reductive release as a mechanism for iron uptake from ferrioxamine B by Chlorella vulgaris. Plant Physiol 85: 751-756.

Amin SA, Green DH, Hart MC, Küpper FC, Sunda WG, Carrano CJ. (2009). Photolysis of iron siderophore chelates promotes bacterial algal mutualism. Proc Natl Acad Sci USA 106: 17071-17076.

Aristilde L, Xu Y, Morel FMM. (2012). Weak organic ligands enhance zinc uptake in marine phytoplankton. Environ Sci Technol 46: 5438-5445.

Barbeau K, Rue EL, Bruland KW, Butler A. (2001). Photochemical cycling of iron in the surface ocean mediated by microbial iron (III)-binding ligands. Nature 413: 409-413.

Borer PM, Sulzberger B, Reichard P, Kraemer SM. (2005). Effect of siderophores on the light-induced dissolution of colloidal iron (III)(hydr) oxides. Mar Chem 93: 179-193.

Boyd PW, Jickells T, Law CS, Blain S, Boyle EA, Buesseler KO et al. (2007). Mesoscale iron enrichment experiments 1993-2005: synthesis and future directions. Science 315: 612-617.

Brand LE. (1991). Minimum iron requirements of marine phytoplankton and the implications for the biogeochemical control of new production. Limnol Oceanogr 36: 1756-1771.

Chen M, Dei RCH, Wang W-X, Guo L. (2003). Marine diatom uptake of iron bound with natural colloids of different origins. Mar Chem 81: 177-189.

Chen M, Wang W-X. (2008). Accelerated uptake by phytoplankton of iron bound to humic acids. Aquat Biol 3: 155-166.
Eckhardt U, Buckhout TJ. (1998). Iron assimilation in Chlamydomonas reinhardtii involves ferric reduction and is similar to Strategy I higher plants. J Exp Bot 49: 1219-1226.

Gervais F, Riebesell U, Gorbunov MY. (2002). Changes in primary productivity and chlorophyll a in response to iron fertilization in the Southern Polar Frontal Zone. Limnol Oceanogr 47: 1324-1335.

Gledhill M, van den Berg CMG. (1994). Determination of complexation of iron (III) with natural organic complexing ligands in seawater using cathodic stripping voltammetry. Mar Chem 47: 41-54.

Gledhill M, Buck KN. (2012). The organic complexation of iron in the marine environment: a review. Front Microbiol 3.

Gustafsson Jon, Petter. (2010). Visual MINTEQ, 3.0 edn. Available at http://www2.lwr.kth.se/English/Oursoftware/vminteq/.

Hassler CS, Schoemann V. (2009). Bioavailability of organically bound Fe to model phytoplankton of the Southern Ocean. Biogeosciences 6: 2281-2296.

Hopkinson BM, Morel FMM. (2009). The role of siderophores in iron acquisition by photosynthetic marine microorganisms. Biometals 22: 659-669.

Hopkinson BM, Barbeau KA. (2012). Iron transporters in marine prokaryotic genomes and metagenomes. Environ Microbiol 14: 114-128.

Hudson RJM, Morel FMM. (1990). Iron transport in marine phytoplankton: kinetics of cellular and medium coordination reactions. Limnol Oceanogr 35: 1002-1020.

Hudson RJM, Covault DT, Morel FMM. (1992). Investigations of iron coordination and redox reactions in seawater using ${ }^{59} \mathrm{Fe}$ radiometry and ion-pair solvent extraction of amphiphilic iron complexes. Mar Chem 38: 209-235 .

Hudson RJM, Morel FMM. (1993). Trace metal transport by marine microorganisms: implications of metal coordination kinetics. Deep Sea Res Pt I 40: 129-150.

Hutchins DA, Witter AE, Butler A, Luther GW. (1999). Competition among marine phytoplankton for different chelated iron species. Nature 400: 858-861.

Johnson KS, Gordon RM, Coale KH. (1997). What controls dissolved iron concentrations in the world ocean? Mar Chem 57: 137-161.

Jones GJ, Palenik BP, Morel FMM. (1987). Trace metal reduction by phytoplankton: the role of plasmalemma redox enzymes. J Phycol 23: 237-244.

Kraemer SM. (2004). Iron oxide dissolution and solubility in the presence of siderophores. Aquat Sci 66: 3-18.

Kranzler C, Lis H, Shaked Y, Keren N. (2011). The role of reduction in iron uptake processes in a unicellular, planktonic cyanobacterium. Environ Microbiol 13: 2990-2999.

Kranzler C, Lis H, Finkel OM, Schmetterer G, Shaked Y, Keren N. (2014). Coordinated transporter activity shapes high-affinity iron acquisition in cyanobacteria. ISME J 8: 409-417.

Kuma K, Matsunaga K. (1995). Availability of colloidal ferric oxides to coastal marine phytoplankton. Mar Biol 122: 1-11.

Kustka AB, Shaked Y, Milligan AJ, King DW, Morel FMM. (2005). Extracellular production of superoxide by marine diatoms: contrasting effects on iron redox chemistry and bioavailability. Limnol Oceanogr 50: 1172-1180.

Kustka AB, Allen AE, Morel FMM. (2007). Sequence analysis and transcriptional regulation of iron acquisition genes in two marine diatoms. I Phycol 43: 715-729. 
Lammers PJ, Sanders-Loehr J. (1982). Active transport of ferric schizokinen in Anabaena sp. J Bacteriol 151: 288-294.

Lane ES, Semeniuk DM, Strzepek RF, Cullen JT, Maldonado MT. (2009). Effects of iron limitation on intracellular cadmium of cultured phytoplankton: implications for surface dissolved cadmium to phosphate ratios. Mar Chem 115: 155-162.

Lis H, Shaked Y. (2009). Probing the bioavailability of organically bound iron: a case study in the Synechococcus-rich waters of the Gulf of Aqaba. Aquat Microb Ecol 56: 241-267.

Maldonado MT, Price NM. (1996). Influence of N substrate on $\mathrm{Fe}$ requirements of marine centric diatoms. Mar Ecol Prog Ser 141: 161-172.

Maldonado MT, Price NM. (2001). Reduction and transport of organically bound iron by Thalassiosira Oceanica (Bacillariophyceae). J Phycol 37: 298-310.

Maldonado MT, Strzepek RF, Sander S, Boyd PW. (2005). Acquisition of iron bound to strong organic complexes, with different $\mathrm{Fe}$ binding groups and photochemical reactivities, by plankton communities in Fe-limited subantarctic waters. Global Biogeochem Cy 19: GB4S23.

Maldonado MT, Allen AE, Chong JS, Lin K, Leus D, Karpenko $\mathrm{N}$ et al. (2006). Copper-dependent iron transport in coastal and oceanic diatoms. Limnol Oceanogr 51: 1729-1743.

Mann EL, Chisholm SW. (2000). Iron limits the cell division rate of Prochlorococcus in the eastern equatorial Pacific. Limnol Oceanogr 45: 1067-1076.

Marchetti A, Maldonado MT, Lane ES, Harrison PJ. (2006). Iron requirements of the pennate diatom Pseudonitzschia: comparison of oceanic (high-nitrate, low-chlorophyll waters) and coastal species. Limnol Oceanogr 51: 2092-2101.

Martin JH, Fitzwater S. (1988). Iron deficiency limits phytoplankton growth in the north-east Pacific subarctic. Nature 331: 947-975.

Martin JH. (1990). Glacial-interglacial CO2 change: the iron hypothesis. Paleoceanography 5: 1-13.

Martin JH, Gordon RM, Fitzwater SE. (1991). The case for iron. Limnol Oceanogr 36: 1793-1802.

McKay RML, Bullerjahn GS, Porta D, Brown ET, Sherrell RM, Smutka TM et al. (2004). Consideration of the bioavailability of iron in the North American Great Lakes: development of novel approaches toward understanding iron biogeochemistry. Aquat Ecosyst Health 7: 475-490.

Millero FJ. (1998). Solubility of Fe (III) in seawater. Earth Planet Sci Lett 154: 323-329.

Moore JK, Doney SC, Glover DM, Fung IY. (2001). Iron cycling and nutrient-limitation patterns in surface waters of the World Ocean. Deep Sea Res Pt II 49: 463-507.

Morel FMM, Kustka AB, Shaked Y. (2008). The role of unchelated Fe in the iron nutrition of phytoplankton. Limnol Oceanogr 53: 400.

Morel FMM, Hering JG. (1993). Principles and Applications of Aquatic Chemistry. John Wiley \& Sons.

Nodwell LM, Price NM. (2001). Direct use of inorganic colloidal iron by marine mixotrophic phytoplankton. Limnol Oceanogr 46: 765-777.
North RL, Guildford SJ, Smith REH, Havens SM, Twiss MR. (2007). Evidence for phosphorus, nitrogen, and iron colimitation of phytoplankton communities in Lake Erie. Limnol Oceanogr 52: 315-328.

Pierre JL, Fontecave M, Crichton RR. (2002). Chemistry for an essential biological process: the reduction of ferric iron. Biometals 15: 341-346.

Raven JA, Evans MC, Korb RE. (1999). The role of trace metals in photosynthetic electron transport in O2evolving organisms. Photosynth Res 60: 111-150.

Rubin M, Berman-Frank I, Shaked Y. (2011). Dust-and mineral-iron utilization by the marine dinitrogen-fixer Trichodesmium. Nat Geosci 4: 529-534.

Rue EL, Bruland KW. (1995). Complexation of iron (III) by natural organic ligands in the Central North Pacific as determined by a new competitive ligand equilibration/ adsorptive cathodic stripping voltammetric method. Mar Chem 50: 117-138.

Salmon TP, Rose AL, Neilan BA, Waite TD. (2006). The FeL model of iron acquisition: Nondissociative reduction of ferric complexes in the marine environment. Limnol Oceanogr 51: 1744-1754.

Shaked Y, Kustka AB, Morel FMM, Erel Y. (2004). Simultaneous determination of iron reduction and uptake by phytoplankton. Limnol Oceanogr Methods 2: 137-145.

Shaked Y, Kustka AB, Morel FMM. (2005). A general kinetic model for iron acquisition by eukaryotic phytoplankton. Limnol Oceanogr 50: 872-882.

Shaked Y, Lis H. (2012). Disassembling iron availability to phytoplankton. Front Microbiol 3: 1-26.

Shi D, Xu Y, Hopkinson BM, Morel FMM. (2010). Effect of ocean acidification on iron availability to marine phytoplankton. Science 327: 676-679.

Strzepek RF, Maldonado MT, Hunter KA, Frew RD, Boyd PW. (2011). Adaptive strategies by Southern Ocean phytoplankton to lessen iron limitation: Uptake of organically complexed iron and reduced cellular iron requirements. Limnol Oceanogr 56: 1983.

Sulzberger B, Suter D, Siffert C, Banwart S, Stumm W. (1989). Dissolution of Fe (III)(hydr) oxides in natural waters; laboratory assessment on the kinetics controlled by surface coordination. Mar Chem 28: 127-144.

Sunda WG, Huntsman SA. (1995). Iron uptake and growth limitation in oceanic and coastal phytoplankton. Mar Chem 50: 189-206.

Sunda WG, Huntsman SA. (1997). Interrelated influence of iron, light and cell size on marine phytoplankton growth. Nature 390: 389-392.

Sunda WG, Price NM, Morel FMM. (2005). Trace metal ion buffers and their use in culture studies In: Anderson RA (ed). Algal Culturing Techniques. Elsevier Academic Press: Burlington, MA, USA pp 35-63.

Thompson AW. (2009). Iron and prochlorococcus. PhD thesis, Massachusetts Institute of Technology, Cambridge, MA.

Wu J, Luther GW III. (1995). Complexation of Fe (III) by natural organic ligands in the Northwest Atlantic Ocean by a competitive ligand equilibration method and a kinetic approach. Mar Chem 50: 159-177.

Wu J, Boyle E, Sunda WG, Wen LG. (2001). Soluble and colloidal iron in the oligotrophic North Atlantic and North Pacific. Science 293: 847-849.

Supplementary Information accompanies this paper on The ISME Journal website (http://www.nature.com/ismej) 